\title{
A Mathematical Analysis of Dolipore/Parenthesome Structure in Basidiomycetes
}

\author{
By A. MARIE PATTON AND ROGER MARCHANT \\ School of Biological and Environmental Studies, New University of Ulster, \\ Coleraine, County Londonderry, Northern Ireland
}

(Received 30 June 1978)

Measurements were taken on the septal ultrastructure of 13 species of basidiomycete fungi
from eight different orders. A continuum of dolipore size was found as opposed to the two
size-types previously proposed. A cluster analysis was carried out on the measurements to
suggest relationships between the species. Based on this and other published information
on dolipores, possible evolutionary trends in the ultrastructure of the dolipore are discussed.

\section{INTRODUCTION}

The septal pore apparatus of the basidiomycetes was recognized by Buller (1933) as hemispherical pads on either side of the septal pore. Its complex structure was first elucidated by Girbardt (1958) and the structures were later termed dolipore and parenthesome by Moore \& McAlear (1962). Since then, these structures have been found in a wide range of basidiomycetes and a comprehensive review of septal knowledge up to 1967 is given by Bracker (1967). Up to the present, the dolipore/parenthesome septum has been found in all basidiomycete groups with the exception of the Uredinales and Septobasidiales.

In most basidiomycetes the parenthesome takes the form of a dome-shaped cap showing qualitative differences between groups. It is perforate in members of the Agaricales, Aphyllophorales, Phallales, Melanogastrales and Lycoperdales (Thielke, 1972; Moore \& Marchant, 1972; Eymé \& Parriaud, 1970; Brooks, 1975; Marchant, 1969), non-perforate in some Tremellales (Wells, 1964; Moore, 1971), Tulasnellales (Moore, 1978), Dacrymycetales and Auriculariales (Moore \& McAlear, 1962), and is modified into a series of cupulate units in some members of the Tremellales (Khan, 1976; Moore, 1978) and Ustilaginales (Filobasidiaceae) (Moore \& Kreger-van Rij, 1972).

A few workers have taken measurements of dolipores or parenthesomes (Bracker \& Butler, 1963; Wilsenach \& Kessel, 1965; Setliff et al., 1972; Ellis et al., 1972) and, although incomplete, these suggest that there may also be quantitative differences between septa in different groups.

The purpose of this work was to take complete series of measurements on dolipore/ parenthesome septa from a wide variety of basidiomycetes and compare them to see what quantitative differences exist between groups.

\section{METHODS}

The following strains were obtained from the Centraalbureau voor Schimmelcultures, Baarn, The Netherlands: Amanita muscaria (L. ex Fr.) Hooker (CBs 103.42); Auricularia mesenterica (Dicks.) Pers. (CBs 119.34); Auricularia polytricha (Mont.) Sacc. (CBS 439.67); Boletus edulis Bull. ex Fr. (CBs 563.70); Calocera viscosa Pers. (CBS 152.48); Ceratobasidium cornigerum (Bourd.) D. P. Rogers (CBS 148.54); Exidia glandulosa (Bull.) Fr. (CBS 176.38); Exidia truncata Fr. (CBs 216.63); Hydnum septentrionale Fr. (CBs 229.63); Nidularia 

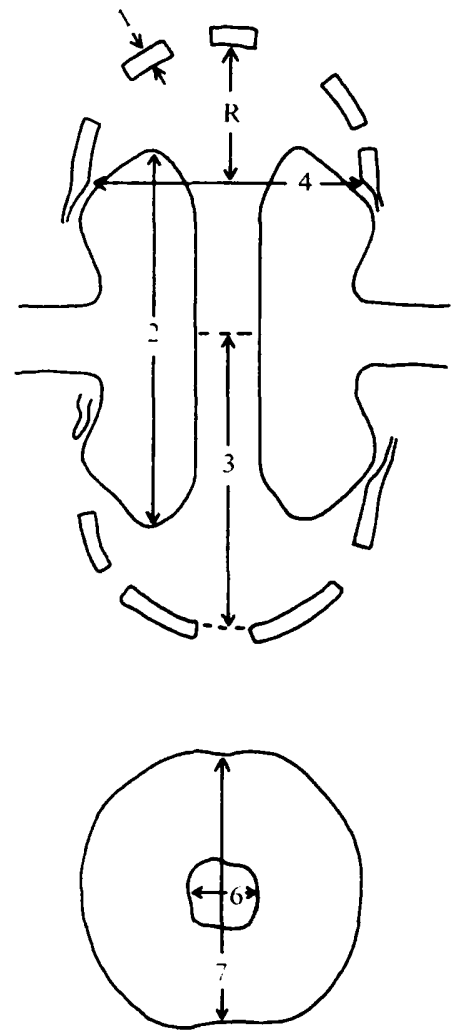

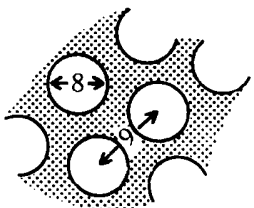

PARAMETERS

1. Parenthesome thickness

2. Septal pore length

3. Distance from parenthesome to septum

4. Parenthesome diameter

5. Deviation of parenthesome shape from hemispherical, i.e.

$\mathrm{R}-\frac{1}{2}$ (parenthesome diameter)

6. Septal pore diameter

7. Pore body diameter

8. Parenthesome hole diameter

9. Distance between centres of adjacent parenthesome holes

Fig. 1. Diagram showing meihods of measurement of dolipore/parenthesome parameters. Parenthesome thickness (1) was measured at up to seven places on each parenthesome if both inner and outer delimiting membranes were clearly resolved. Septal pore length (2) was measured on both swellings and an average length noted. Parameters 3, 4 and 5 were measured for both parenthesomes. Septal pore diameter (6) and parenthesome hole diameter (8) were measured using an acetate sheet on which circles whose diameter increased in $1 \mathrm{~mm}$ steps had been drawn. This allowed the centre of each parenthesome hole to be marked with a pin for measurement 9 . The pore body diameter ( 7 ) was measured at four orientations and an average measurement noted.

confluens Fr. (CBs 744.68); Phallus impudicus L. ex Fr. (CBS 178.57); Polyporus biennis (Bull. ex Fr.) Fr. (CBS 676.70). Many of these strains were clearly dikaryotic, as indicated by the presence of clamp connections; the remainder were also probably dikaryotic. A dikaryotic strain of Schizophyllum commune Fr. $(699 \times 845)$ was kindly provided by Professor J. G. H. Wessels, University of Groningen, The Netherlands. A dikaryotic strain of Agaricus bisporus (Lange) Singer, strain Sindon, was obtained from Dundarg Mushrooms Ltd, Coleraine, Co. Londonderry. A dikaryotic strain of Corticium fuciforme (Berk.) Wakefield was isolated from infected grass in the grounds of the New University of Ulster.

All strains were grown on cellophane laid over $2 \%(\mathrm{w} / \mathrm{v})$ malt agar, except Hydnum septentrionale which was grown directly on malt agar because cellophane reduced the growth rate and altered the growth pattern of this species. Small areas of mycelium from the edges of the colonies were fixed for $1 \mathrm{~h}$ in $3 \%(\mathrm{v} / \mathrm{v})$ acrolein in $0.1 \mathrm{M}$-sodium cacodylate buffer ( $\mathrm{pH} \mathrm{7.2)}$, postfixed for $1 \mathrm{~h}$ in similarly buffered osmium tetroxide, and dehydrated in an acetone series interrupted by staining overnight in $1 \%(w / v)$ uranyl nitrate at the $70 \%$ acetone stage. Polyporus biennis, Ceratobasidium cornigerum, Corticium fuciforme, Schizophyllum commune and Agaricus bisporus were then embedded in Epon 812. Embedding proved a problem with the other 10 species, but was eventually found to be satisfactory after infiltration for $4 \mathrm{~d}$ with Spurr resin (Spurr, 1969). No difference was found in the cutting or staining properties of mycelia embedded in the different resins. Large sections were cut with a diamond knife on a Huxley Ultramicrotome Mark II and lifted routinely on uncoated 400 mesh copper grids, which gave maximum support without the staining problems and loss of resolution associated with support films. Sections were then poststained with lead citrate before examination at $80 \mathrm{kV}$ in an AEI EM6G electron microscope.

Initally problems of stretching or tearing were encountered with silver/grey sections, but section stability, 
Table 1. Mean values (nm) and standard deviations for nine septal measurements (see Fig. 1) on 13 species of basidiomycete

\begin{tabular}{|c|c|c|c|c|c|c|c|c|c|c|}
\hline & 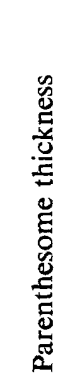 & 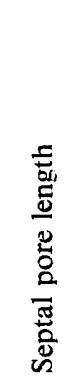 & 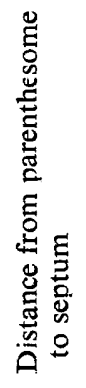 & 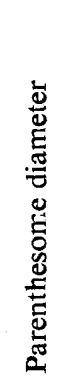 & 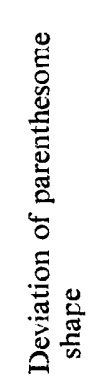 & 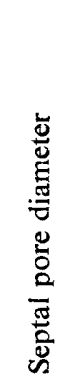 & 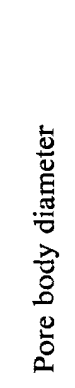 & 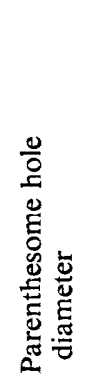 & 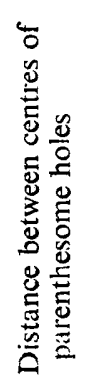 & \\
\hline Species & 1 & 2 & 3 & 4 & 5 & 6 & 7 & 8 & 9 & \\
\hline $\begin{array}{r}\text { 1. Auricularia } \\
\text { polytricha }\end{array}$ & $\begin{array}{r}27 \cdot 5 \\
2 \cdot 8\end{array}$ & $\begin{array}{l}549 \\
129\end{array}$ & $\begin{array}{r}387 \\
92\end{array}$ & $\begin{array}{r}469 \\
87\end{array}$ & $\begin{array}{r}-92 \\
63\end{array}$ & $\begin{array}{r}138 \\
18\end{array}$ & $\begin{array}{r}505 \\
59\end{array}$ & $\begin{array}{l}67 \cdot 2 \\
11\end{array}$ & $\begin{array}{r}110 \\
14\end{array}$ & $\begin{array}{c}\text { Mean } \\
\text { S.D. }\end{array}$ \\
\hline $\begin{array}{l}\text { 2. Calocera } \\
\text { viscosa }\end{array}$ & $\begin{array}{r}24 \cdot 9 \\
2 \cdot 5\end{array}$ & $\begin{array}{r}455 \\
62\end{array}$ & $\begin{array}{r}309 \\
34\end{array}$ & $\begin{array}{r}270 \\
42\end{array}$ & $\begin{array}{r}-85 \\
24\end{array}$ & $\begin{array}{l}89 \\
19\end{array}$ & $\begin{array}{r}419 \\
57\end{array}$ & 0 & $329^{*}$ & \\
\hline $\begin{array}{l}\text { 3. Ceratobasidium } \\
\text { cornigerum }\end{array}$ & $\begin{array}{r}45 \cdot 5 \\
4 \cdot 8\end{array}$ & $\begin{array}{r}1242 \\
131\end{array}$ & $\begin{array}{r}1073 \\
104\end{array}$ & $\begin{array}{l}923 \\
175\end{array}$ & $\begin{array}{r}+12 \\
83\end{array}$ & $\begin{array}{r}266 \\
41\end{array}$ & $\begin{array}{r}1126 \\
141\end{array}$ & $\begin{array}{r}332 \\
39\end{array}$ & $\begin{array}{r}412 \\
59\end{array}$ & \\
\hline $\begin{array}{l}\text { 4. Corticium } \\
\text { fuciforme }\end{array}$ & $\begin{array}{r}34 \cdot 8 \\
2 \cdot 5\end{array}$ & $\begin{array}{r}858 \\
96\end{array}$ & $\begin{array}{r}717 \\
59\end{array}$ & $\begin{array}{r}499 \\
75\end{array}$ & $\begin{array}{r}+48 \\
56\end{array}$ & $\begin{array}{r}140 \\
32\end{array}$ & $\begin{array}{l}597 \\
108\end{array}$ & $\begin{array}{r}143 \\
8\end{array}$ & $\begin{array}{r}211 \\
33\end{array}$ & \\
\hline $\begin{array}{l}\text { 5. Exidia } \\
\text { glandulosa }\end{array}$ & $\begin{array}{r}24 \cdot 7 \\
0 \cdot 8\end{array}$ & $\begin{array}{r}383 \\
37\end{array}$ & $\begin{array}{r}282 \\
23\end{array}$ & $\begin{array}{r}344 \\
35\end{array}$ & $\begin{array}{r}-70 \\
23\end{array}$ & $\begin{array}{l}94 \\
16\end{array}$ & $\begin{array}{r}382 \\
41\end{array}$ & 0 & $457^{*}$ & \\
\hline $\begin{array}{l}\text { 6. Nidularia } \\
\text { confluens }\end{array}$ & $\begin{array}{r}28 \cdot 4 \\
2 \cdot 2\end{array}$ & $\begin{array}{r}541 \\
78\end{array}$ & $\begin{array}{r}383 \\
48\end{array}$ & $\begin{array}{r}394 \\
42\end{array}$ & $\begin{array}{r}-64 \\
47\end{array}$ & $\begin{array}{r}114 \\
28\end{array}$ & $\begin{array}{r}441 \\
48\end{array}$ & $\begin{array}{r}51 \cdot 0 \\
8 \cdot 0\end{array}$ & $\begin{array}{l}95 \\
13\end{array}$ & \\
\hline $\begin{array}{l}\text { 7. Phallus } \\
\text { impudicus }\end{array}$ & $\begin{array}{r}28 \cdot 3 \\
2 \cdot 1\end{array}$ & $\begin{array}{r}630 \\
68\end{array}$ & $\begin{array}{r}463 \\
51\end{array}$ & $\begin{array}{r}575 \\
77\end{array}$ & $\begin{array}{r}-114 \\
44\end{array}$ & $\begin{array}{r}141 \\
24\end{array}$ & $\begin{array}{r}605 \\
54\end{array}$ & $\begin{array}{l}70 \cdot 3 \\
20\end{array}$ & $\begin{array}{r}133 \\
27\end{array}$ & \\
\hline $\begin{array}{c}\text { 8. Polyportus } \\
\text { biennis }\end{array}$ & $\begin{array}{r}29 \cdot 9 \\
2 \cdot 3\end{array}$ & $\begin{array}{r}599 \\
84\end{array}$ & $\begin{array}{r}449 \\
62\end{array}$ & $\begin{array}{r}522 \\
75\end{array}$ & $\begin{array}{r}-90 \\
60\end{array}$ & $\begin{array}{r}174 \\
32\end{array}$ & $\begin{array}{r}589 \\
53\end{array}$ & $\begin{array}{c}72 \cdot 0 \\
6\end{array}$ & $\begin{array}{r}318 \\
20\end{array}$ & \\
\hline $\begin{array}{l}\text { 9. Schizophyllum } \\
\text { commune }\end{array}$ & $\begin{array}{r}30 \cdot 5 \\
2 \cdot 8\end{array}$ & $\begin{array}{r}587 \\
84\end{array}$ & $\begin{array}{r}466 \\
54\end{array}$ & $\begin{array}{r}477 \\
77\end{array}$ & $\begin{array}{r}-28 \\
58\end{array}$ & $\begin{array}{r}107 \\
13\end{array}$ & $\begin{array}{r}469 \\
48\end{array}$ & $\begin{array}{l}89 \cdot 4 \\
13\end{array}$ & $\begin{array}{r}135 \\
15\end{array}$ & \\
\hline $\begin{array}{l}\text { 10. Agaricus } \\
\text { bisporus }\end{array}$ & $\begin{array}{r}29 \cdot 6 \\
1.6\end{array}$ & $\begin{array}{r}706 \\
47\end{array}$ & $\begin{array}{r}518 \\
63\end{array}$ & $\begin{array}{r}514 \\
65\end{array}$ & $\begin{array}{r}-45 \\
32\end{array}$ & $\begin{array}{r}113 \\
22\end{array}$ & $\begin{array}{l}655 \\
135\end{array}$ & $\begin{array}{l}80 \cdot 1 \\
10\end{array}$ & $\begin{array}{r}133 \\
16\end{array}$ & \\
\hline $\begin{array}{l}\text { 11. Amanita } \\
\text { muscaria }\end{array}$ & $\begin{array}{r}29 \cdot 3 \\
2 \cdot 7\end{array}$ & $\begin{array}{l}591 \\
137\end{array}$ & $\begin{array}{l}460 \\
107\end{array}$ & $\begin{array}{r}478 \\
57\end{array}$ & $\begin{array}{r}-27 \\
59\end{array}$ & $\begin{array}{r}175 \\
20\end{array}$ & $\begin{array}{r}584 \\
68\end{array}$ & $\begin{array}{c}88 \cdot 3 \\
8\end{array}$ & $\begin{array}{r}131 \\
11\end{array}$ & \\
\hline $\begin{array}{l}\text { 12. Boletus } \\
\text { edutis }\end{array}$ & $\begin{array}{r}29 \cdot 7 \\
1 \cdot 7\end{array}$ & $\begin{array}{r}587 \\
65\end{array}$ & $\begin{array}{r}457 \\
44\end{array}$ & $\begin{array}{r}530 \\
58\end{array}$ & $\begin{array}{r}-58 \\
38\end{array}$ & $\begin{array}{r}152 \\
3\end{array}$ & $\begin{array}{r}621 \\
5\end{array}$ & $\begin{array}{l}92 \cdot 4 \\
11\end{array}$ & $\begin{array}{r}136 \\
12\end{array}$ & \\
\hline $\begin{array}{l}\text { 13. Hydnum } \\
\text { septentrionale }\end{array}$ & $\begin{array}{r}31 \cdot 3 \\
1 \cdot 5\end{array}$ & $\begin{array}{r}577 \\
14\end{array}$ & $\begin{array}{r}488 \\
35\end{array}$ & $\begin{array}{r}440 \\
46\end{array}$ & $\begin{array}{r}-20 \\
24\end{array}$ & $\begin{array}{r}147 \\
14\end{array}$ & $\begin{array}{r}459 \\
43\end{array}$ & $\begin{array}{c}78 \cdot 8 \\
7\end{array}$ & $\begin{array}{r}134 \\
18\end{array}$ & \\
\hline
\end{tabular}

Each mean value for species 1 to 9 is based on at least 26 measurements, but for parameters 1,8 and 9 , for which each photograph vielded more than one measurement, the mean values are based on 30 to 196 measurements. For species 10 to 13 , mean values of parameters 2, 3, 4, 5, 6 and 7 are based on 4 to 7 measurements and parameters 1,8 and 9 are based on 8 to 32 measurements.

* Calculated values: assuming that the median longitudinal section through the parenthesome is the arc of a larger circle, the distance from one parenthesome edge to the other was calculated.

an important factor when measurements are to be taken, was greatly improved by routinely cutting thicker (gold/silver) sections. The effects of stretching or tearing were further minimized by scanning only those grid squares where the section had no holes and was supported on all sides. The effect of section compression was minimized by measuring a large sample of dolipores.

Three sets of photographs were taken for each of nine species (species 1 to 9 in Table 1). (1) Approx. 30 median longitudinal sections: these were taken because not only is the dolipore symmetrical around this median but, since most dolipores only have one true median in this plane, a sample of 30 different dolipores was ensured. (2) Approx. 30 transverse sections through the dolipore: these were necessary to measure pore diameter. (3) Approx. 30 tangential glancing sections through parenthesome holes (where holes were present). 


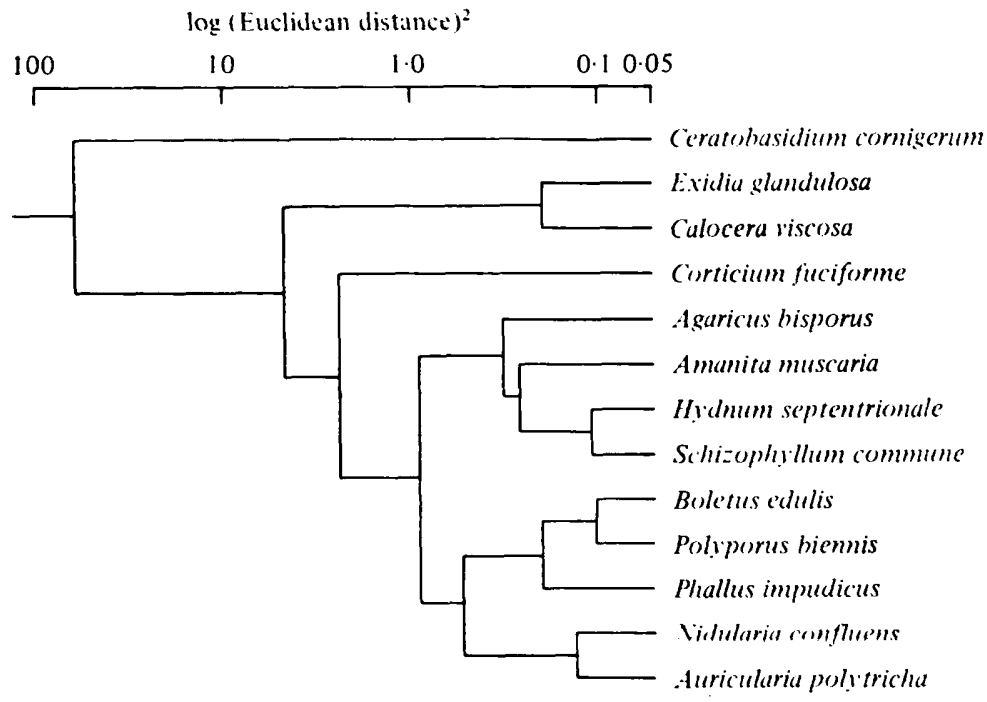

Fig. 2. Dendrogram showing the result of a cluster analysis using Ward's method.

A smaller number of photographs in each of these categories was taken for species 10 to 13 in Table 1. During the investigation the electron microscope was regularly calibrated using a diffraction grating, so that accurate measurements could be taken from each photograph. The data in Table 1 were standardized and a cluster analysis based on Ward's method (Ward, 1963) was carried out using the CLUSTAN 1A package (Wishart, 1969).

Sections of each species were also stained by the method of Thiéry (1967). Sections were lifted on uncoated, 200 mesh, stainless-steel grids and treated as follows: (i) $1 \%(\mathrm{v} / \mathrm{v})$ aqueous periodic acid for $30 \mathrm{~min}$; (ii) four $5 \mathrm{~min}$ washes in water; (iii) $1 \%(\mathrm{w} / \mathrm{v})$ thiosemicarbazide in $10 \%(\mathrm{v} / \mathrm{v})$ acetic acid for $40 \mathrm{~min}$; (iv) three $5 \mathrm{~min}$ washes in $10 \%(\mathrm{v} / \mathrm{v})$ acetic acid; (v) washed in a graded series from $10 \%(\mathrm{v} / \mathrm{v})$ acetic acid to water; and (vi) exposed to osmium tetroxide vapour at $67^{\circ} \mathrm{C}$ for $1 \mathrm{~h}$. The sections were examined without further staining.

\section{RESULTS}

For each parameter in Fig. 1 a mean value and standard deviation were calculated for each species, producing the matrix shown in Table 1. Most of the standard deviations are falsely large because of the method"of collection of the data, and reveal more about the degree of stretching and compression of the sections than about the inherent variability of the septal structure.

The wide variation in size of the septal pore apparatus can be clearly seen by comparing the micrographs of species such as Calocera viscosa (Fig. 9), a small species with nonperforate parenthesomes, with intermediate-sized species such as Phallus impudicus (Fig. 4) and Schizophyllum commune (Fig. 10), both of which have parenthesomes with numerous holes, and with large species such as Ceratobasidium cornigerum (Fig. 11), which have a few large holes in the parenthesome.

A cluster analysis was initially carried out on the mean measurements for the first nine species in Table 1, since the mean values for the remainder were based on fewer measurements. However, when the analysis was repeated on the complete matrix $(13 \times 9)$ the four extra species were added into the previous clustering pattern without basically altering it. The dendrogram produced by the larger cluster analysis is shown in Fig. 2.

It was the intention to enlarge the matrix yet again by the addition of some qualitative characters such as 'type of occlusion of pore channel' and 'degree of reticulation of dolipore 

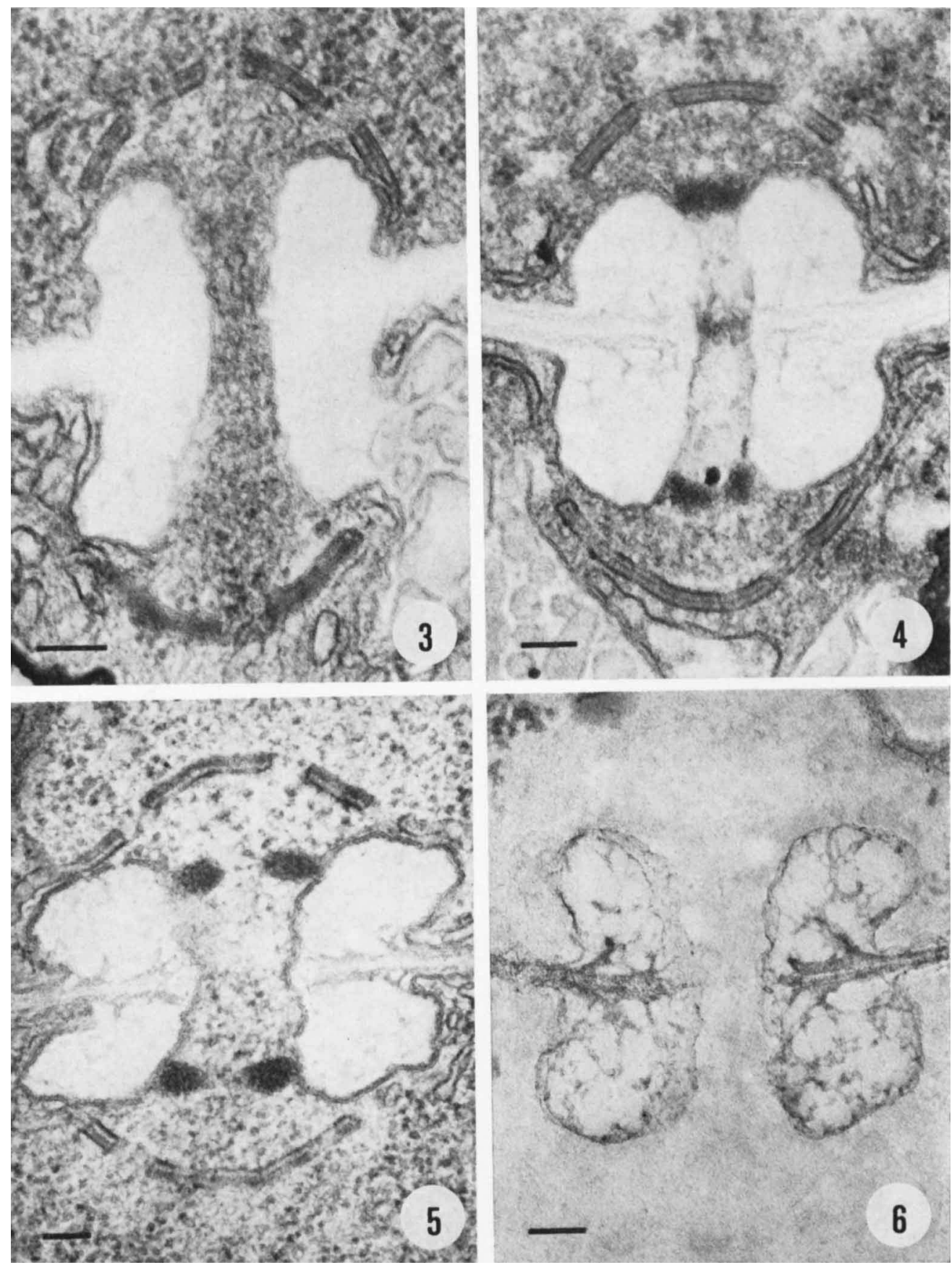

All bar markers represent $100 \mathrm{~nm}$

Fig. 3. Median longitudinal section through a dolipore/parenthesome septum of Auricularia polytricha.

Fig. 4. Median longitudinal section through a dolipore/parenthesome septum of Phallus impudicus. Fig. 5. Median longitudinal section through a dolipore/parenthesome septum of Polyporus biennis. Fig. 6. Thiéry-stained median longitudinal section through a dolipore/parenthesome septum of Polyporus biennis. Note that the parenthesomes have not stained. 

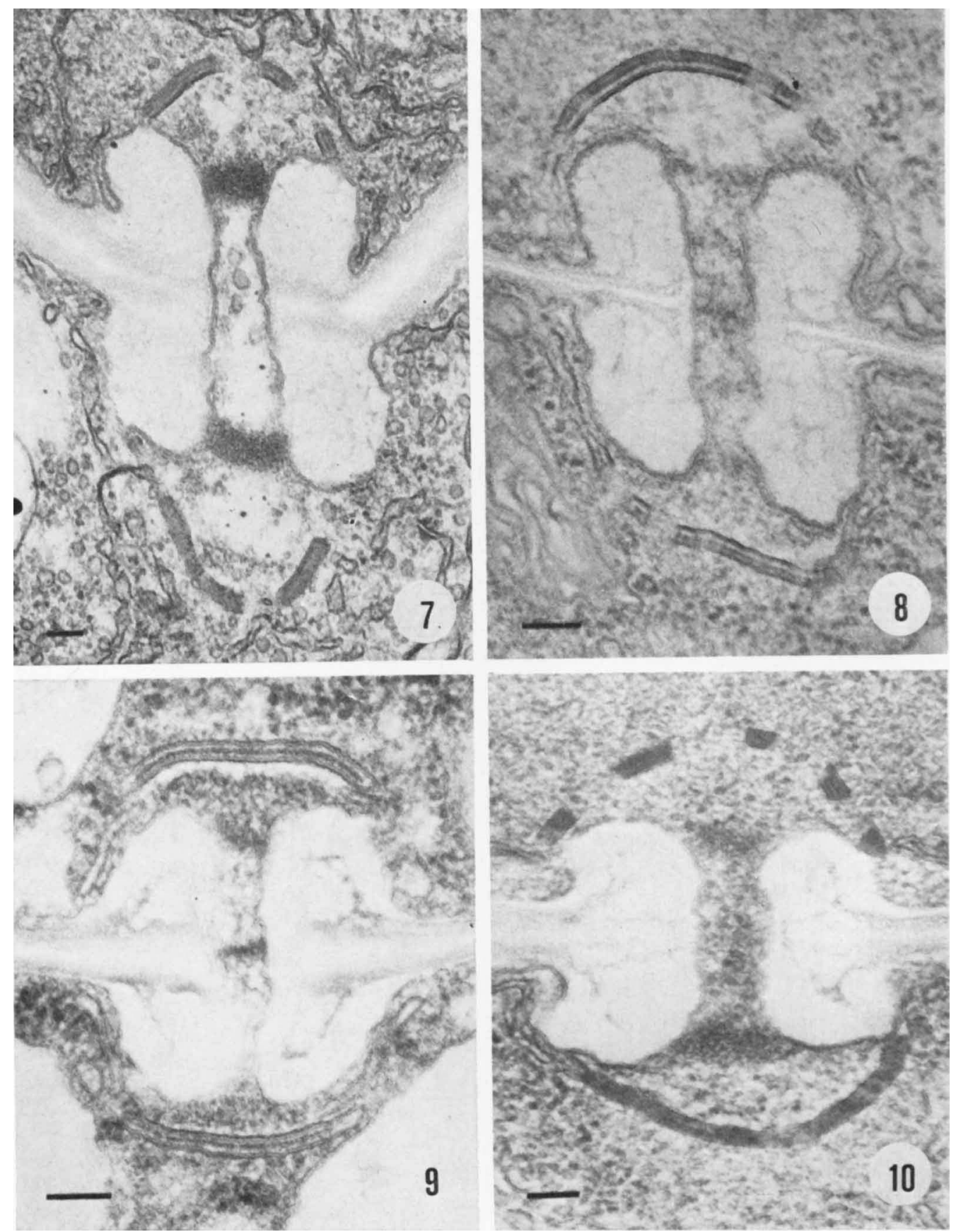

All bar markers represent $100 \mathrm{~nm}$

Fig. 7. Median longitudinal section through a dolipore/parenthesome septum of Corticium fuciforme.

Fig. 8. Median longitudinal section through a dolipore/parenthesome septum of Nidularia confluens.

Fig. 9. Median longitudinal section through a dolipore/parenthesome septum of Calocera viscosa. Fig. 10. Median longitudinal section through a dolipore/parenthesome septum of Schizophyllum commune. 

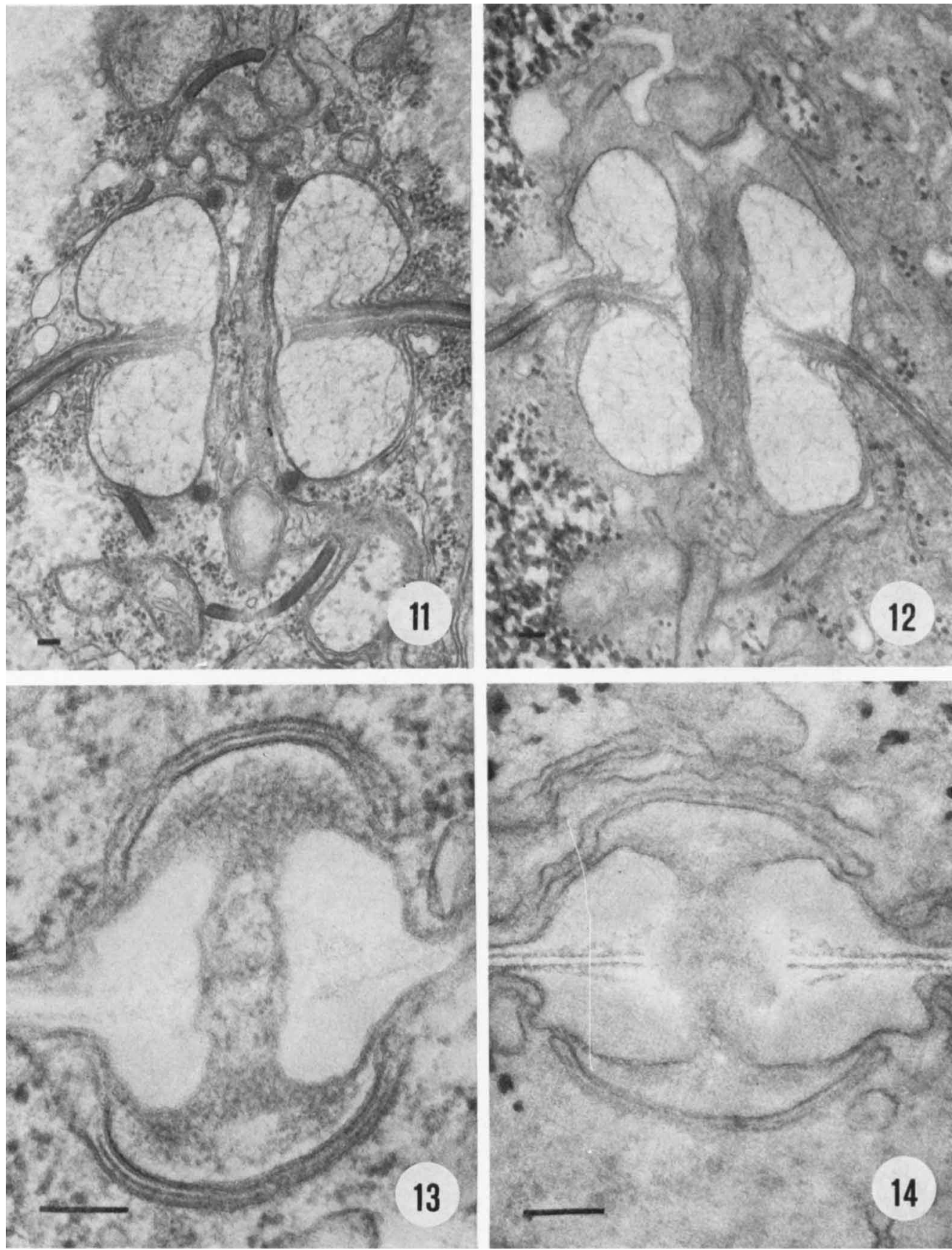

All bar markers represent $100 \mathrm{~nm}$

Fig. 11. Median longitudinal section through a dolipore/parenthesome septum of Ceratobasidium cornigerum. Note the presence of mitochondria in the pore channel and in areas under the parenthesomes.

Fig. 12. Thiéry-stained median longitudinal section through a dolipore/parenthesome septum of Ceratobasidium cornigerum.

Fig. 13. Median longitudinal section through a dolipore/parenthesome septum of Exidia glandulosa. Note the granular occlusions which extend from the pore channel into the region enclosed by the parenthesome.

Fig. 14. Thiéry-stained median longitudinal section through a dolipore/parenthesome septum of Exidia glandulosa. In this species the parenthesomes have stained. 

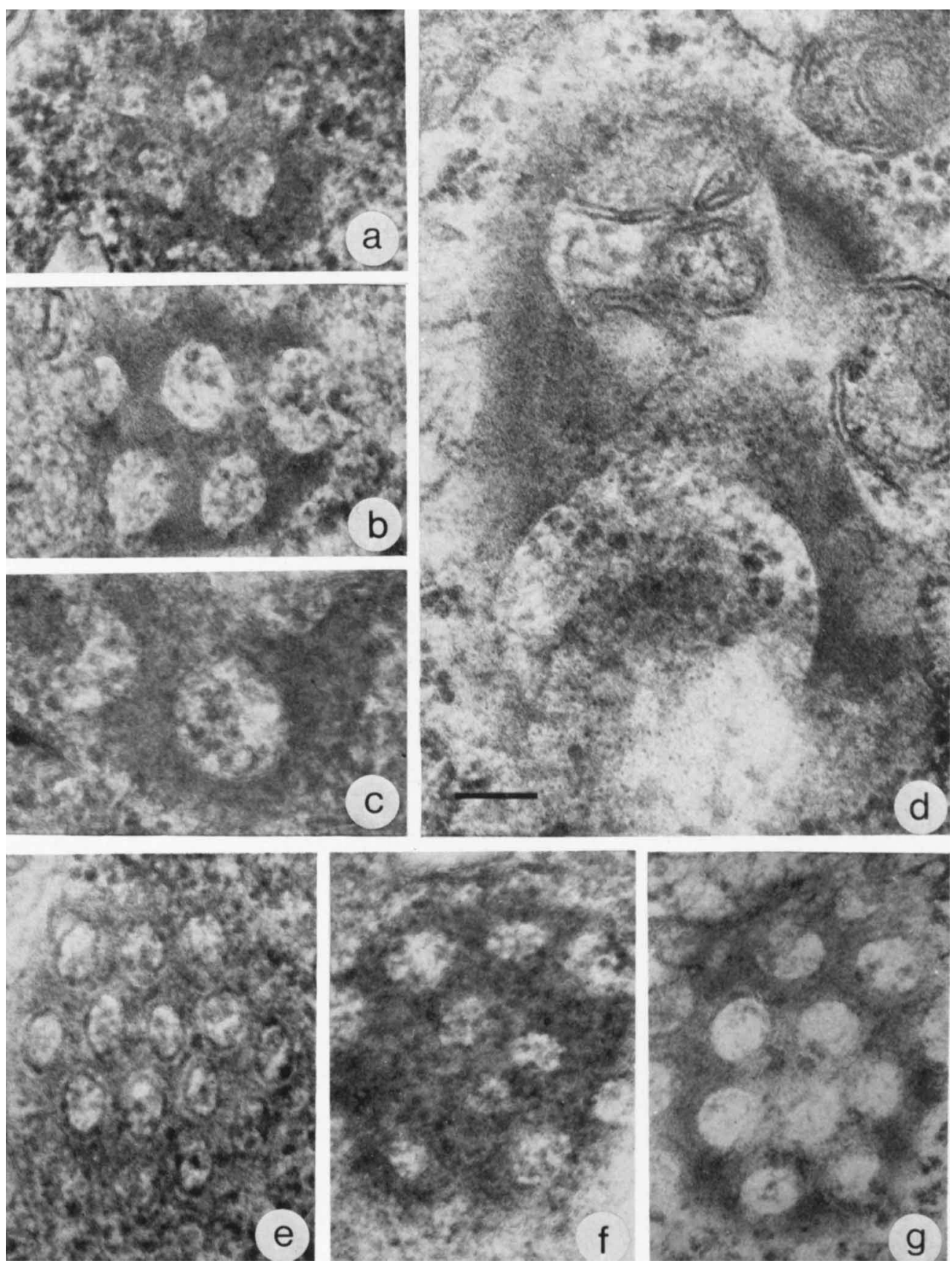

Fig. 15. Tangential glancing sections through the parenthesomes of (a) Auricularia polytricha, (b) Schizophyllum commune, (c) Corticium fuciforme, (d) Ceratobasidium cornigerum, (e) Nidularia confluens, $(f)$ Phallus impudicus, $(g)$ Polyporus biennis. Bar marker represents $100 \mathrm{~nm}$. 

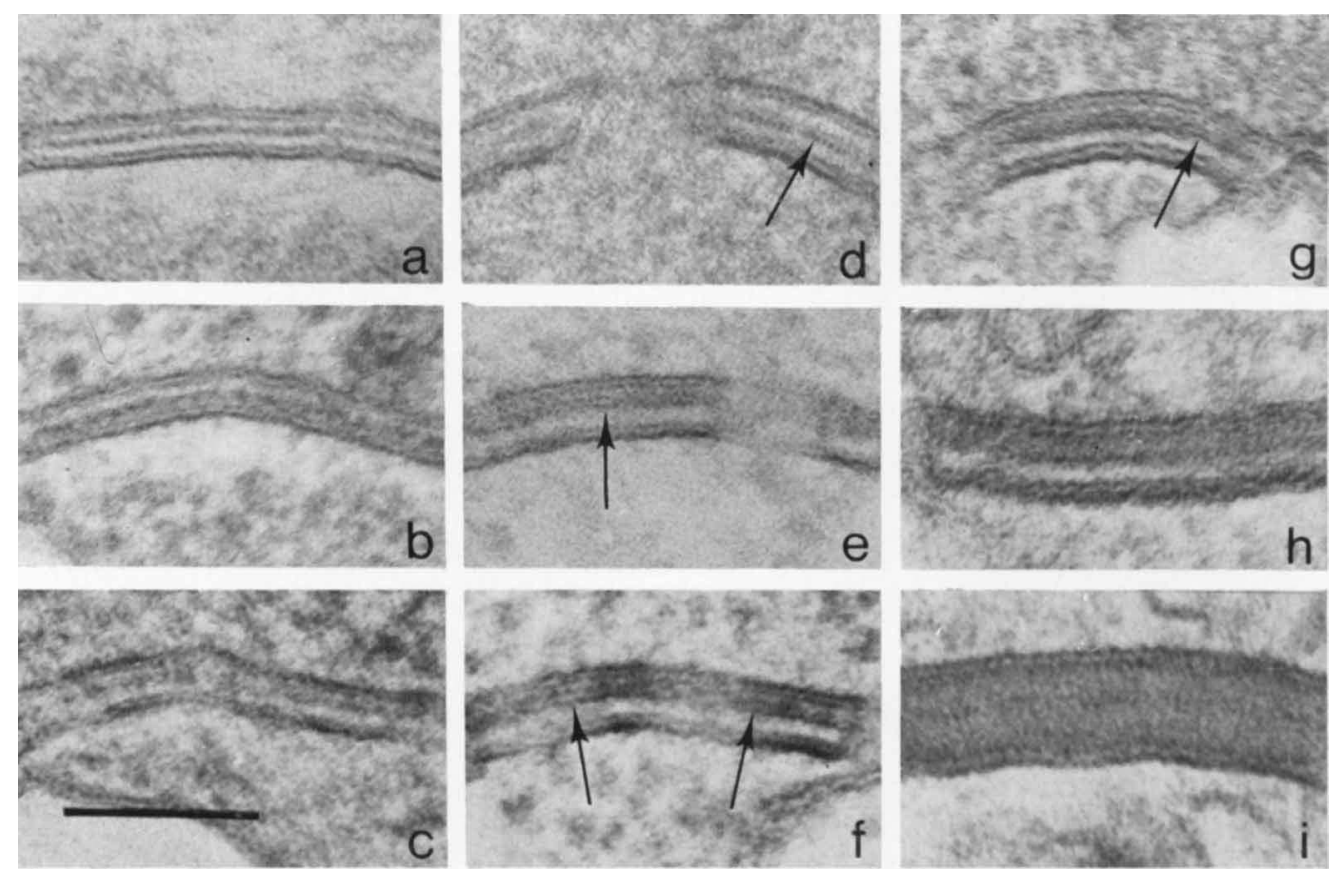

Fig. 16. Sections through parenthesomes, arranged in order of increasing thickness: (a) Exidia glandulosa, (b) Calocera viscosa, (c) Auricularia polytricha, (d) Phallus impudicus, (e) Nidularia confluens, $(f)$ Polyporus biennis, $(g)$ Schizophyllum commune, $(h)$ Corticium fuciforme, (i) Ceratobasidium cornigerum. Arrows indicate central unit membrane. Bar marker represents $100 \mathrm{~nm}$.

swellings'. However, examination of the photographs for each species showed that these characters were very variable. In some of the slow-growing species, for example Auricularia polytricha and Nidularia confluens, most of the cells were dead, except at the growing edge of the mycelium. Sections were therefore cut close to the hyphal tips and none of the dolipores had occluded pore channels (see, for example, Figs 3 and 8); but it was not considered valid to score these species thus since occlusions may have been present a little further back from the edge of the mycelium, if, as Bracker \& Butler (1963) suggest, "plugging' only occurs in the dolipores of older hyphae. This may indeed be the case since in Ceratobasidium cornigerum some of the pore channels had no occlusions, some had openring shaped occlusions (Fig. 11) and others were almost completely occluded.

As regards reticulation of the swellings, some species clearly had a network of material which stained heavily with lead or Thiéry stain, for example Polyporus biennis (Figs 5 and 6), Corticium fuciforme (Fig. 7) and Ceratobasidium cornigerum (Figs 11 and 12), while others clearly did not, for example Exidia glandulosa (Figs 13 and 14) and Auricularia polytricha (Fig. 3). However, in Nidularia confluens the swellings appeared reticulate in some cases (Fig. 8), non-reticulate in others, and some dolipores were found with the half of the dolipore on one side of the septum reticulate, and the half on the other side non-reticulate. Also, although in the strain of Agaricus bisporus examined the dolipore swellings (from an ageing part of the mycelium) were not reticulate, those in a strain of the same species studied by Thielke (1972) were reticulate.

Thus occlusion of the pore channel and reticulation of the dolipore swellings appeared to be characters which may undergo changes during differentiation of fungal hyphae and so were not suitable for use as characters in the present study.

The micrographs of glancing sections through parenthesome holes from different species at the same magnification (Fig. 15) show that there is a wide range of sizes of parenthesome 


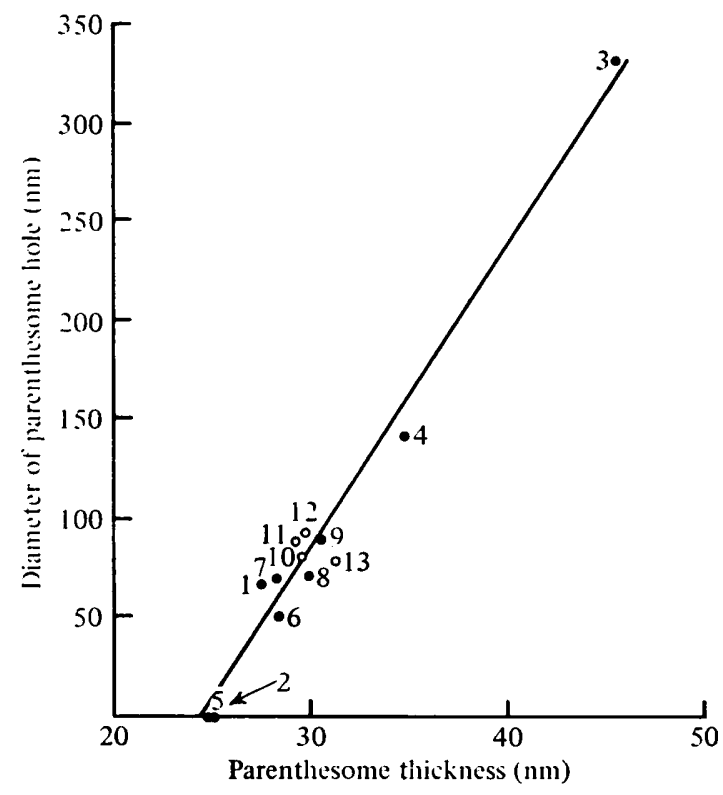

Fig. 17. Relationship between the thickness of the parenthesome and the diameter of the parenthesome holes. Numbers refer to species as in Table 1.

Table 2. Correlation matrix, showing the correlation coefficient $(r)$ for each pair of parameters (see Fig. 1)

\begin{tabular}{|c|c|c|c|c|c|c|c|}
\hline 1 & 2 & 3 & 4 & 5 & 6 & 7 & 8 \\
\hline 0.968 & & & & & & & \\
\hline 0.986 & 0.992 & & & & & & \\
\hline 0.895 & 0.905 & 0.895 & & & & & \\
\hline 0.695 & 0.640 & 0.697 & 0.379 & & & & \\
\hline 0.847 & 0.809 & 0.819 & 0.892 & 0.380 & & & \\
\hline 0.893 & 0.934 & 0.914 & 0.958 & 0.415 & 0.883 & & \\
\hline 0.986 & 0.972 & 0.980 & 0.937 & 0.632 & 0.877 & 0.935 & \\
\hline 0.238 & 0.232 & 0.266 & 0.137 & 0.190 & $0 \cdot 130$ & 0.254 & 228 \\
\hline
\end{tabular}

holes; parenthesome thickness is also very variable (Fig. 16). A linear relationship exists between these two parameters (Fig. 17); regression analysis showed a significant correlation (at $0.1 \%$ level) with a coefficient $r=0.986$.

A matrix was obtained (Table 2 ) giving the correlation coefficient for every possible combination of pairs of parameters. There was a high degree of correlation $(r=0.809$ to 0.992 ) between all pairs except those involving parameters 5 or 9 . This suggests that, in general, as one parameter increases so do the others, i.e. as the pore body diameter increases (a size range of comparable pore bodies is shown in Fig. 18), so does the septal pore diameter and the length of the dolipore (i.e. septal pore length). Also, as the dolipore increases in size so do most of the parenthesome parameters, i.e. the diameter and thickness of the parenthesome and the size of its holes. Parameter 5 is an index of parenthesome shape and as such is not affected by size, but parameter 9 is the distance between parenthesome hole centres and so might be expected to increase with increasing parenthesome diameter and hole size. If we picture the distance between holes as the width of the parenthesome bridge between adjacent holes (i.e. the distance between adjacent hole centres minus 1 hole diameter), it is clear from Fig. 19 that the width of the bridge does not increase in step with the hole size but fluctuates about a mean of $53 \mathrm{~nm}$. Thus the large holes in the Ceratobasidium 

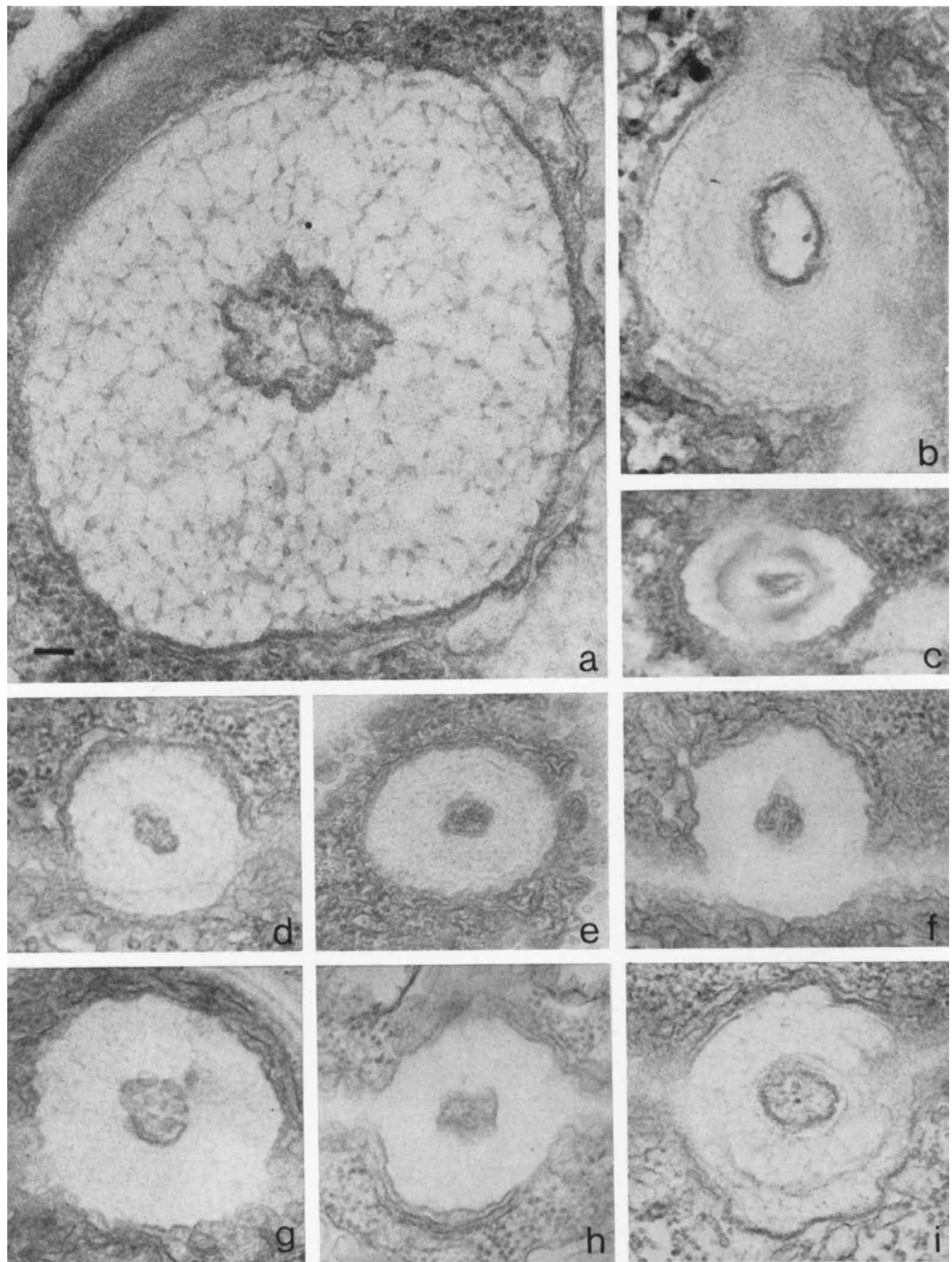

Fig. 18. Transverse sections through the dolipore sweilings of (a) Ceratobasidium cornigerum, $(b)$ Corticium fuciforme, (c) Calocera viscosa, $(d)$ Nidularia confluens, (e) Schizophyllum commune, $(f)$ Auricularia polytricha, (g) Phallus impudicus, (h) Exidia glandulosa, (i) Polyporus biennis. Bar marker represents $100 \mathrm{~nm}$. 


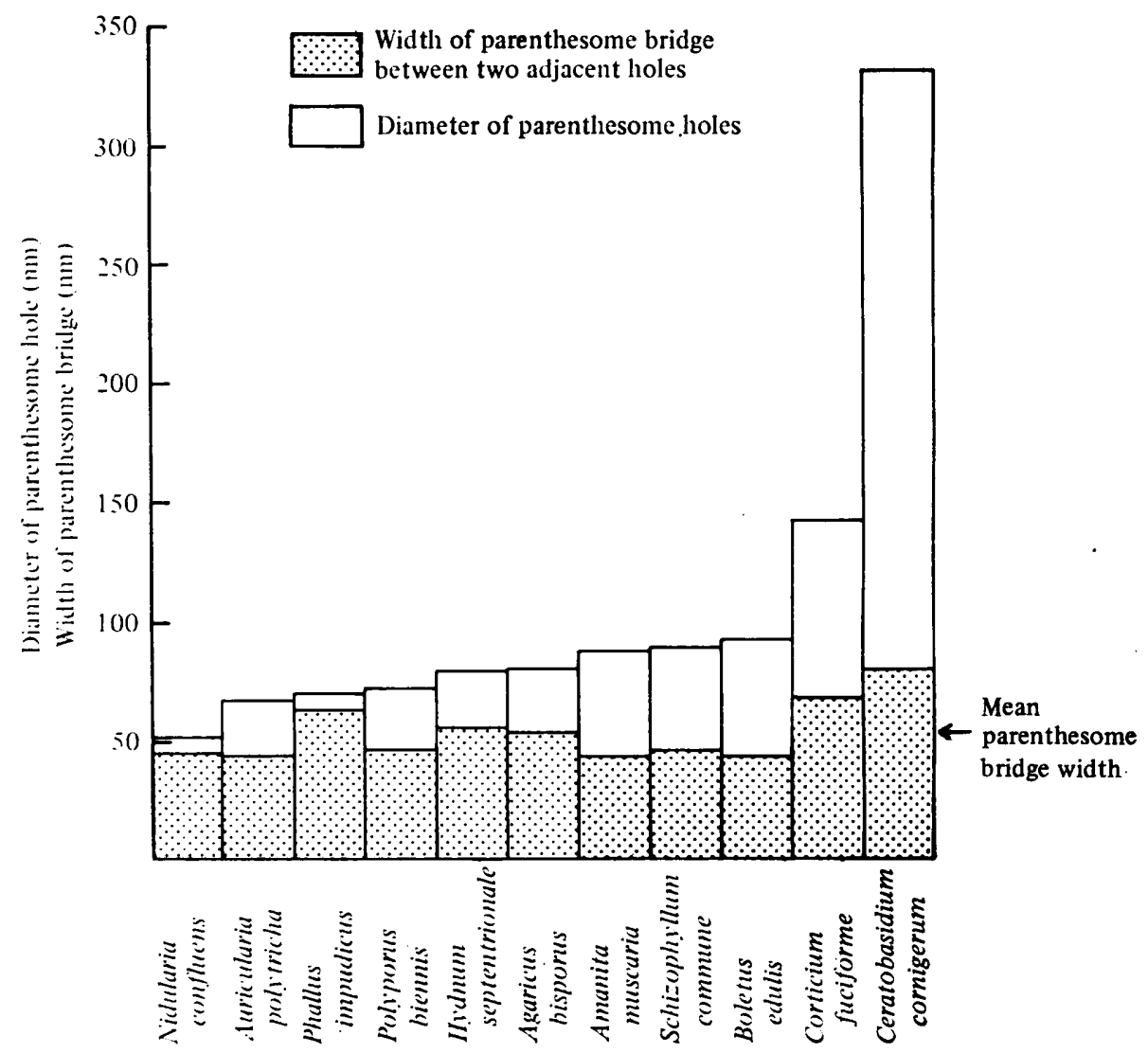

Fig. 19. Histogram showing the parenthesome hole diameter and the corresponding width of the parenthesome bridge between two adjacent holes. Species are arranged in order of increasing parenthesome hole diameter.

cornigerum parenthesome are relatively much closer together than the smaller holes of the other species. This is substantiated by calculation of the percentage of hole in the parenthesome area (based on a hexagonal arrangement of holes), which was $59 \%$ in Ceratobasidium cornigerum, 40 to $42 \%$ in Corticium fuciforme, Boletus edulis, Amanita muscaria and Schizophyllum commune, 31 to $34 \%$ in Hydnum septentrionale, Agaricus bisporus, Polyporus biennis and Auricularia polytricha, and only $26 \%$ in Phallus impudicus and Nidularia confluens.

\section{DISCUSSION}

There are obvious quantitative differences between the dolipore/parenthesome septa in basidiomycetes of different groups. Those with non-perforate parenthesomes are considerably smaller than the two main clusters of species containing members of the Agaricales and Aphyllophorales. The two species at the other end of the size scale are Ceratobasidium cornigerum and Corticium fuciforme. The Ceratobasidiaceae, previously in the Tulasnellales, have been reclassified as members of the Corticiaceae (Shaffer, 1975). This is fortunate in the present context since the Tulasnella species studied by Moore (1978) has a dolipore with non-perforate parenthesomes and is similar in size to Exidia glandulosa. Corticium (Rhizoctonia) solani has dolipores in the same size range as Ceratobasidium cornigerum, while those of Corticium fuciforme are much smaller. That Ceratobasidium cornigerum and Corticium solani have, based on other characters, both been placed in the genus Pellicularia Cooke, a 
segregate from the genus Corticium, would suggest that the separation of Corticium fuciforme from Ceratobasidium cornigerum in the cluster analysis (Fig. 2) is a true distinction.

The Auricularia species examined in the present study, Auricularia polytricha and Auricularia mesenterica, both have perforate parenthesomes, while the species previously considered as Auricularia auricularis (= Auricularia auricula-judae), which was examined by Moore \& McAlear (1962) and has since been transferred to the genus Hirneola and reexamined by Moore (1978), has non-perforate parenthesomes. Again this discrepancy underlines an area of uncertainty in classification. Donk (1958) segregated the genus Hirneola Fr. from Auricularia on growth form, Auricularia auricula-judae being placed in the genus Hirneola as Hirneola auricula-judae while Auricularia polytricha and Auricularia mesenterica remained in the genus Auricularia.

Exidia glandulosa and Calocera viscosa, which have non-perforate parenthesomes, are also separated off together on the basis of quantitative parameters. Measurements made on published micrographs of other septa with non-perforate parenthesomes, i.e. Exidia nucleata (Wells, 1964), Dacrymyces deliquescens and Auricularia auricularis (= Hirneola auricula-judae sensu Donk) (Moore \& McAlear, 1962), suggest that they are all in the same size range as Exidia glandulosa and Calocera viscosa. [The only major anomalous observations are those of Setliff et al. (1972) and Traquair \& McKeen (1978) who have reported non-perforate parenthesomes in two field-collected members of the Polyporaceae.] It is also interesting to note that Filobasidium capsuligenum (Moore \& Kreger-van Rij, 1972) has a septal pore length and parenthesome thickness almost identical to that of Exidia glandulosa, and the structure in Filobasidium capsuligenum may represent a multiple non-perforate parenthesome situation. The evidence supports the suggestion of Wilsenach \& Kessel (1965) that modifications of septal pore structure within the basidiomycetes may have phylogenetic significance, particularly as the septal complex is likely to be a conserved structure not subject to rapid evolutionary changes. Shaffer (1975) points out that the division of the basidiomycetes into Hemibasidiomycetes, Heterobasidiomycetes and Homobasidiomycetes is in accord with many taxonomists' evolutionary ideas, but the Heterobasidiomycetes lack a significant unifying diagnostic feature. Perhaps the possession of a small dolipore with a non-perforate parenthesome is such a feature. If this were the case, Hirneola (with nonperforate parenthesomes) would remain in the Heterobasidiomycetes while Auricularia would be removed. In the cluster analysis, the septum most similar to that of Auricularia polytricha is Nidularia confluens, so perhaps the Auriculariales and Nidulariales are closely linked phylogenetically.

The majority of the species studied in this work belonged to the Agaricales and Aphyllophorales and, with the exception of Corticium fuciforme and Ceratobasidium cornigerum, all these species have similar dolipores in the middle size range. The gasteromycetes Phallus impudicus and Nidularia confluens occupy the same cluster, which also contains the two representatives of the pore-bearing fungi Boletus edulis and Polyporus biennis. The remaining major cluster comprises Agaricus bisporus, Amanita muscaria, Hydnum septentrionale and Schizophyllum commune. The analysis has thus separated these toothed and gilled fungi from the pore-bearing species.

The increase in parenthesome thickness as the holes in its structure get larger may have some structural significance, as an increase in thickness may be necessary to support the larger holes which are also relatively closer together. However, since neither the composition nor the mechanical properties of the material comprising the parenthesomes is known, the reason for this relationship remains obscure. Also the increase in thickness of the parenthesome is not a proportional one; all the parenthesomes are bound top and bottom by similar unit membranes (Fig. 16) but the position and configuration of material between these membranes varies. Ceratobasidium cornigerum has widely spaced delimiting membranes and the area between is filled with a dense even matrix. At the other extreme, Exidia glandulosa and Calocera viscosa have only a thin layer of densely staining matrix midway 


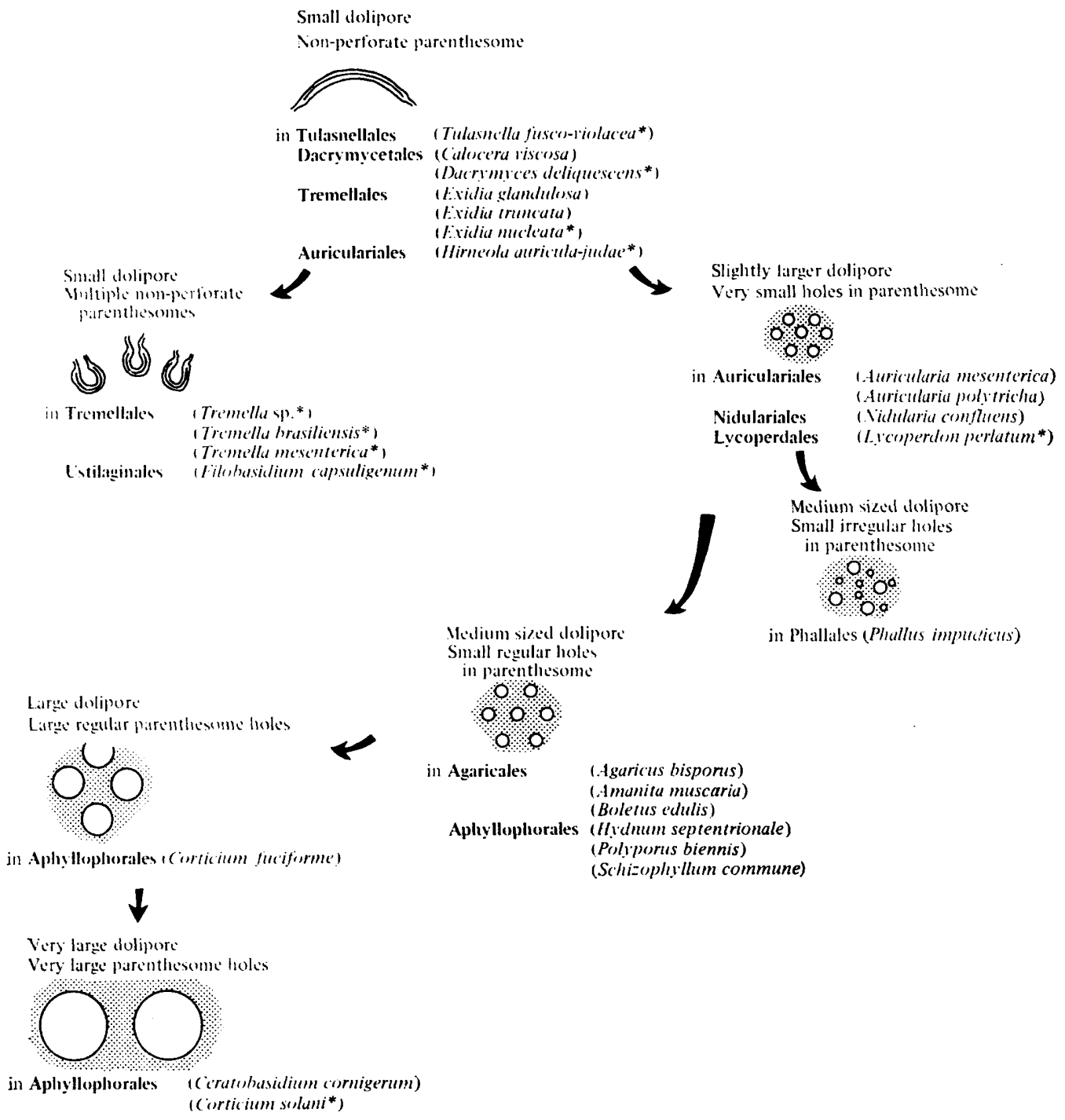

Fig. 20. Diagram illustrating a possible phylogeny of the dolipore/parenthesome septum of the basidiomycetes. (* Structural types in these species were derived from published literature.)

between the membranes, while in slightly thicker parenthesomes this layer appears to be resolved into a third unit membrane (arrowed in Fig. 16) as described by Moore \& Patton (1975).

The function of the dolipore/parenthesome may be to maintain the strict segregation of nuclei found in many basidiomycetes, whilst still allowing cytoplasmic continuity where necessary. For instance, Trinci (1971) suggested that a number of hyphal compartments contribute material for the extension of the hyphal apex. In basidiomycetes the unplugged dolipore apparatus may allow transport of material from a supporting region behind the growing hyphal tips. If this were the case, the factors determining the size of particles which can move through the septum are (i) the diameter of the parenthesome holes and (ii) the diameter of the pore channel. In all species except Ceratobasidium cornigerum and Corticium fuciforme the parenthesome hole diameter is the limiting dimension; in Corticium fuciforme both dimensions are equal, while in Ceratobasidium cornigerum the limiting aperture is the 
septal pore. Thus in all species except Ceratobasidium cornigerum the parenthesome may function to grade particles before they reach the pore channel.

Wilsenach \& Kessel (1965) suggested, from the evidence available at that time, that there were two types of dolipore, a small Polyporus-type with a large number of small parenthesome holes and a large Rhizoctonia-type with a small number of large parenthesome holes. The results of the present study suggest that the range of structure is continuous in nature, and it is possible to construct a simple phylogeny of the dolipore (Fig. 20).

This work was carried out while the senior author held a postgraduate studentship from the Department of Education, Northern Ireland.

\section{REFERENCES}

BRACKER, C. E. (1967). Ultrastructure of fungi. Annual Review of Phytopathology 5, 343-374.

Bracker, C. E. \& Butler, E. E. (1963). The ultrastructure and development of septa in hyphae of Rhizoctonia solani. Mycologia 55, 35-58.

BRoOKs, S. D. (1975). The presence of dolipore septa in Nia vibrissa and Digitatispora marina. Mycologia 67, 172-174.

BULLER, A. H. R. (1933). The translocation of protoplasm through septate mycelium of certain Pyrenomycetes, Discomycetes and Hymenomycetes. In Reseurches on Fungi, vol. V, pp. 75-167. London: Longmans.

Donk, M. A. (1958). The generic names proposed for hymenomycetes. VIII. Auriculariaceae, Septobasidiaceae, Tremellaceae, Dacrymycetaceae. Taxon 7, 164-178, 193-207, 236-250.

Ellis, T. T., ROGERS, M. A. \& Mims, C. W. (1972). The fine structure of the septal pore cap in Coprinus stercorarius. Mycologia 64, 681-688.

Eymé, J. \& Parriaud, H. (1970). Au sujet de l'infrastructure des hyphes de Clathrus cancellatus Tournefort, champignon gastéromycète. Comptes rendus hebdomadaire des séances de l'Académie des sciences, Série D 270, 1890-1892.

Girbardt, M. (1958). Ưber die Substruktur von Polystictus versicolor L. Archiv für Mikrobiologie 28, 255-269.

KHAN, S. R. (1976). Ultrastructure of the septal pore apparatus of Tremella. Journal of General Microbiology 97, 339-342.

Marchant, R. (1969). The fine structure and development of the fructification of Lycoperdon perlatum. Transactions of the British Mycological Society 53, 63-68.

MoORE, R. T. (1971). An alternative concept of the fungi based on their ultrastructure. In Recent Adlances in Microbiology, Proceedings of 10th International Congress for Microbiology, Mexico City, 1970, vol. 10, 49-64.

MoORE, R. T. (1978). Taxonomic significance of septal ultrastructure with particular reference to the jelly fungi. Mycologia (in the Press).

MOORE, R. T. \& KREGER-VAN RiJ, N. J. W. (1972). Ultrastructure of Filobasidium Olive. Canadian Journal of Microbiology 18, 1949-1951.
MOORE, R. T. \& MARChant, R. (1972). Ultrastructural characterisation of the basidiomycete septum of Polyporus biennis. Canadian Journal of Botuny 50, 2463-2469.

MoORe, R. T. \& MCAleak, J. H. (1962). Fine structure of mycota. 7. Observations on septa of ascomycetes and basidiomycetes. American Journul of Botany 49, 86-94.

Moore, R. T. \& Patton, A. M. (1975). Parenthesome fine structure in Pleurotus cystidiosus and Schizophyllum commune. Mycologia 67, 1200 1205.

Setliff, E. C., MacDonald, W. L. \& Patton, R. F. (1972). Fine structure of the septal pore apparatus in Polyporus tomentosus, Poria latemarginata and Rhizoctonia solani. Canadian Journal of Botany 50, 2559-2563.

ShafFer, R. L. (1975). The major groups of basidiomycetes. Mycologia 67, 1-18.

SPURR, A. R. (1969). A low-viscosity epoxy resin embedding medium for electron microscopy. Journal of Ultrastructure Research 26, 31-43.

THIELKE, C. (1972). Die Dolipore der Basidiomyceten. Archiv für Mikrobiologie 82, 31-37.

Thiéry, J. P. (1967). Mise en évidence des polysaccharides sur coupes fines en microscopie électronique. Journal de Microscopie 6, 987-1018.

Traquair, J. A. \& McKeen, W. E. (1978). Ultrastructure of the dolipore-parenthesome septum in Hirschioporus pargamenus (Polyporaceae). Canadian Journal of Microbiology 24, 767-771.

TRINCI, A. P. J. (1971). Influence of the peripheral growth zone on the radial growth rate of fungal colonies. Journal of General Microbiology 67, 325-344.

WAKD. J.H. (1963). Hierarchical grouping to optimise an objective function. Journal of the American Statistical Association 58, 236-244.

WeLLS, K. (1964). The basidia of Exidia nucleata. I. Ultrastructure. Mycologia 56, 327-341.

Wilsenach, R. \& KeSSel, M. (1965). On the function and structure of the septal pore of Polyporus rugulosus. Journal of General Microbiology 40, $397-400$.

WISitART, D. (1969). An algorithm for hierarchical classifications. Biometrics 25, 165-170. 